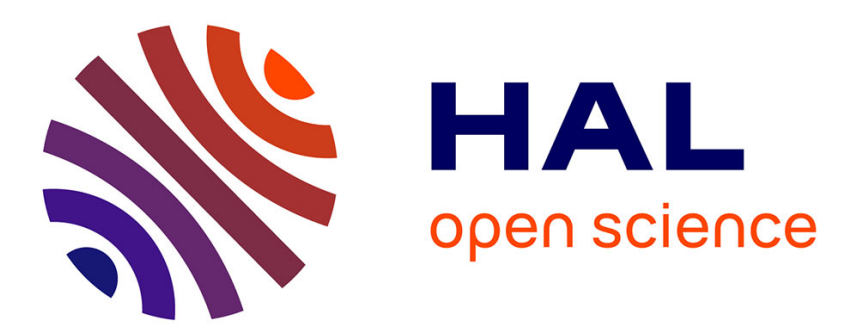

\title{
Plasma diagnostics in pulsed laser deposition of GaLaS chalcogenides
}

Gloria Oana Pompilian, Silviu Gurlui, Petr Němec, Virginie Nazabal, Michael Ziskind, Cristian Focsa

\section{- To cite this version:}

Gloria Oana Pompilian, Silviu Gurlui, Petr Němec, Virginie Nazabal, Michael Ziskind, et al.. Plasma diagnostics in pulsed laser deposition of GaLaS chalcogenides. Applied Surface Science, 2013, 278, pp.352-356. 10.1016/j.apsusc.2012.11.069 . hal-00878952

\section{HAL Id: hal-00878952}

\section{https://hal-univ-rennes1.archives-ouvertes.fr/hal-00878952}

Submitted on 31 Oct 2013

HAL is a multi-disciplinary open access archive for the deposit and dissemination of scientific research documents, whether they are published or not. The documents may come from teaching and research institutions in France or abroad, or from public or private research centers.
L'archive ouverte pluridisciplinaire HAL, est destinée au dépôt et à la diffusion de documents scientifiques de niveau recherche, publiés ou non, émanant des établissements d'enseignement et de recherche français ou étrangers, des laboratoires publics ou privés. 


\title{
Plasma Diagnostics in Pulsed Laser Deposition of GaLaS Chalcogenides
}

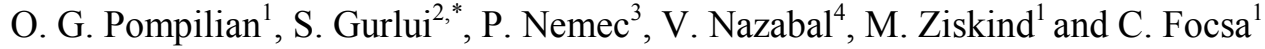 \\ ${ }^{1}$ Laboratoire de Physique des Lasers, Atomes et Molécules (UMR 8523), Université Lille 1, \\ 59655 Villeneuve d'Ascq cedex, France \\ ${ }^{2}$ Physics Department, Alexandru Ioan Cuza University of Iasi, 700506 Iasi, Romania \\ ${ }^{3}$ Faculty of Chemical Technology, University of Pardubice, \\ Studentska 573, 53210 Pardubice, Czech Republic \\ ${ }^{4}$ Laboratoire des Verres et Céramiques, Université de Rennes 1, \\ Campus de Beaulieu, 35042 Rennes cedex, France \\ *Corresponding author: sgurlui@uaic.ro
}

\begin{abstract}
The aim of this work is to characterize the ejection plume obtained by laser ablation of GaLaS (GLS) samples in order to better understand the ablation phenomena for optimizing the pulsed laser deposition of chalcogenide thin films. The dynamics of the plasma between target and substrate was investigated through timeand space-resolved optical emission spectroscopy. High-resolution optical spectra have been recorded in the UVVIS range using a 500-mm focal length monochromator and a fast gate ICCD camera. From the space-time evolution of the optical signals, the velocities of various species (including neutrals and ions) have been derived. Using the relative intensity method, the space- and time-evolution of the excitation temperature and electronic density have been determined. A complex behavior of the laser ablation plasma has been revealed.
\end{abstract}

\section{Keywords: pulsed laser deposition, plasma dynamics, optical emission spectroscopy, chalcogenides}

\section{Introduction}

Amorphous chalcogenides represent an important segment of IR-transparent materials with multiple applications in, e.g. the development of amplifiers and laser sources, optical sensors and all-optical processing components based on non-linear properties [1-5]. In this frame, a special chalcogenide glasses class, namely gallium lanthanum sulphide (GLS), has been evidenced (in particular when doped with rare earth elements) as an attractive non-toxic alternative to arsenic-based glasses, with optical transparency from the visible to infrared wavelengths, thermal stability, high refractive indices, high rare-earth solubility, high transition temperature and large photoinduced effects [6-9]. These glasses are stable, hard, and non-hygroscopic and can be involved in a wide range of novel opto-electronic applications based on their photo-stimulated properties (absorption edge shifts, photo-induced refractive index changes, photo-sensitivity etc.) [10-12].

For some of the applications listed above (especially those related to integrated optics), the processing of the chalcogenide glasses in form of thin films is necessary. Numerous methods of preparation are available (spin coating, thermal evaporation in vacuum, ionic and magnetron sputtering, CVD etc.), yet synthesis of chalcogenide thin films of complex composition, desired stoichiometry, good homogeneity and adhesion to the substrate and other specific physico-chemical properties is often found to be a difficult task for these "classical" methods. Pulsed laser deposition (PLD) evolved as one of the prospective techniques in this field, due to the simplicity of its principle, the possibility to obtain stoichiometric transfer of target material to the substrate and to fabricate films of unusual composition [3]. Although the PLD technique has been employed for almost two decades [13] to grow chalcogenide thin films, the control and optimization of the deposition parameters are still generally done in an empirical manner. For the detailed understanding of the processes connected with PLD and particularly for the optimization of the PLD of amorphous chalcogenide films, studying the dynamics of the plasma plume formed during laser ablation is appealing. Despite the numerous works available in the literature on the PLD growth of amorphous chalcogenides and related materials, only few of them tackled this issue using optical and electrical investigation methods $[14,15]$. Some authors characterized the composition of the ablation plume in terms of atoms, molecules or clusters by using Time-of-Flight Mass Spectrometry [16, 17]. 
The aim of this work is therefore to investigate the dynamics of plasma plume generated by nanosecond laser ablation of GLS chalcogenide under vacuum. The behaviour of the GLS plasma formation was investigated through time- and space-resolved high-resolution optical emission spectroscopy (OES) and fast gate ICCD imaging. From the space-time evolution of the optical signals, the velocities of various species present in the plasma (including neutrals and ions) along with temporal and spatial evolution of associated excitation temperatures and electronic densities have been derived.

\section{Experimental details}

The experimental set-up employed for these measurements has been described previously [18-21]. A schematic view is presented in Figure 1. The GLS chalcogenide target (20 mm diameter, $5 \mathrm{~mm}$ thick disk) is placed on a micrometric precision multi-axis translation-rotation stage in a $\sim 101$ vacuum chamber evacuated to a base pressure of $1 \times 10^{-6}$ Torr by a $550 \mathrm{l} / \mathrm{s}$ turbomolecular pump (Agilent Technologies TV-551) coupled to a 12.6 $\mathrm{m}^{3} / \mathrm{h}$ dry fore pump (Agilent Technologies TS-300). The second harmonic $(\lambda=532 \mathrm{~nm}$ ) of a $10 \mathrm{~ns}$ Nd:YAG pulsed laser beam (Continuum Surelite III-10) is focused (at normal incidence) by a $\mathrm{f}=25 \mathrm{~cm}$ lens onto the GLS target, through a $1 \mathrm{~mm}$ diameter hole manufactured in the substrate holder used for thin film deposition. The estimated spot diameter at the impact point has been $\sim 700 \mu \mathrm{m}$ for a laser energy of $15 \mathrm{~mJ} / \mathrm{pulse}$, leading to a fluence of $\sim 4 \mathrm{~J} / \mathrm{cm}^{2}$. The laser ablation plasma emission was visible to the naked-eye on a distance of $\sim 1 \mathrm{~cm}$ along the normal to the target, expanding on several $\mathrm{mm}$ on the transversal direction. The formation and dynamics of the plasma plume have been studied by means of a high-resolution monochromator (Acton SP2500i, $500 \mathrm{~mm}$ focal length) and an intensified CCD camera (Roper Scientific PIMAX2-1003-UNIGEN2, 1024X1024 pixels, minimum gating time $2 \mathrm{~ns}$ ). The monochromator is fitted with one mirror and two diffraction gratings (300 1/mm, blaze at $300 \mathrm{~nm}$, and $24001 / \mathrm{mm}$, blaze at $240 \mathrm{~nm}$ ) mounted on the same three-position turret, which allows an easy switching between imaging, low-resolution, and high-resolution spectroscopy experiments. For the imaging experiments, a Nikon objective was used to form the image of the whole plasma plume on the ICCD array through the kinematic entrance slit (12 mm x $12 \mathrm{~mm}$ opening) of the spectrometer and with the turret fixed in the mirror position. The ICCD camera was triggered on the TTL Q-switch output of the ablation laser $(10 \mathrm{~Hz}$ repetition rate), and an internal routine was used to increment the delay between the laser pulse and the gate opening. For this configuration, gate widths of $5 \mathrm{~ns}$ were usually employed, in order to catch as much as possible sharp temporal snapshots in the space-time evolution of the plume. Averaging on 20 snapshots for each delay has been performed. For spectrally resolved studies, the plasma plume emission was focused on the monochromator entrance slit by a $\mathrm{f}=40 \mathrm{~mm}$ cylindrical lens (see Figure 1). Low-resolution spectra were recorded using the 300 $1 / \mathrm{mm}$ grating and a monochromator entrance slit width of $50 \mu \mathrm{m}$ in order to identify the spectral regions of interest. In this configuration, $\sim 80 \mathrm{~nm}$ broad spectra were recorded for a given position of the grating, with a spectral resolution of $\sim 0.5 \mathrm{~nm}$. Finally, the high-resolution spectra were recorded with the $24001 / \mathrm{mm}$ grating and a slit width of $50 \mu \mathrm{m}$, resulting in a spectral resolution of $\sim 0.06 \mathrm{~nm}$ on $\sim 8 \mathrm{~nm}$ broad spectra for a given grating position. The complete spectrum was obtained by using the "step-and-glue" procedure of the monochromator/camera software, which automatically increments the grating position once a given $(80 \mathrm{~nm}$ or 8 nm wide) spectrum was recorded.

For space-resolved optical emission spectroscopy studies, a $1 \mathrm{~mm}$ x $5 \mathrm{~mm}$ slit was placed in the vacuum chamber, at $40 \mathrm{~mm}$ from the normal to the target (see Figure 1). This slit defined $1 \mathrm{~mm}$ width plasma plume "slices" parallel to the target surface, which were further imaged ( 1:10 magnification) by the cylindrical lens on the monochromator entrance slit. The slit was maintained fixed and, for spatial scanning, we translated the target and the laser focusing lens as a whole (i.e. without modifying the distance between them), as they were both attached to the same XYZ micrometric translation stage. This arrangement ensures the same ablation spot diameter on the target, i.e. the same fluence, for all the experiments performed. With this system, good spatial resolution $(0.2 \mathrm{~mm}$ along the normal to the target, for a monochromator entrance slit of $20 \mu \mathrm{m})$ and $\mathrm{S} / \mathrm{N}$ ratio (usually $>100$ ) have been achieved.

The experimental set-up includes also electrical probes (target potential, Langmuir probes) linked to a fast digitizing oscilloscope ( $2 \mathrm{Ghz}$, LeCroy) for transient plasma sub-ns investigations which are not presented in this paper. 


\section{Results and discussion}

In order to obtain a preliminary insight on the dynamics of the laser GLS ablation plasma plume, ICCD sequential snapshots of the spectrally unresolved plasma optical emission are recorded at various delays (100$1300 \mathrm{~ns}$ ) with respect to the laser pulse (Figure 2). These pictures reveal the formation of a single plasma structure, on the contrary of some previous studies showing a splitting of the plume in two components (fast and slow) $[14,15,20,21]$. The average axial velocity of the maximum emitting point derived from these images $\left(4.4 \times 10^{3} \mathrm{~m} / \mathrm{s}\right)$ is of the same order of magnitude as in the "slow" component of plasma plume recorded for the AsSe system [14] and is lower than the value derived from time-of-flight Langmuir probe experiments on the nanosecond ablation of gadolinium gallium garnet [15]. We emphasize however that this velocity reflects only the evolution of the maximum emitting point in the plasma (which is ruled mainly by excitation collisions and radiative de-excitations), yet individual species with significantly higher velocities can be present in the plume. In order to separate the contribution of each species present in the plasma plume, we have performed a spaceand time-resolved optical emission spectroscopy study using the technique described in [21]. Figure 3 displays an overview of the 250-700 nm spectral range recorded in the vicinity of the target and the assignment of the most intense spectral observed lines. One can easily notice the presence of both neutral and ionic species in the spectrum, and even some signals from double-charged ions in the case of La. By using the scanning capabilities of the ICCD camera, temporal profiles of the emission lines at a given distance from the target can be recorded in seconds, as illustrated in Figure 4. By recording these profiles at various distances from the target $(z)$, and plotting the distance vs the time needed to reach maximum emission, one can derive axial velocities for the individual species of interest. An example is given in Figure 5 for the results obtained in the case of five neutral and singly-charged species of $\mathrm{Ga}, \mathrm{La}$, and $\mathrm{S}$. The velocity values derived for these species and others (not displayed) are summarized in Table 1.These data show the presence of high kinetic energy species in the plume, with velocities in the range of $10^{4} \mathrm{~m} / \mathrm{s}$. This is of practical importance for PLD, as energetic particles hitting the surface of a growing film can influence the nucleation, energy and mobility of adatoms on the surface of the film, by colliding with atoms already adhered to the existing islands, causing bond breaking or even sputtering. The velocity values displayed in Table 1 turn into kinetic energies ranging from $19 \mathrm{eV}$ for $\mathrm{S}^{+}$to $190 \mathrm{eV}$ for $\mathrm{La}^{+}$. It has been shown that for such high kinetic energies, sputtering rates exceeding 0.5 can be reached (Ag atoms, $4.5 \mathrm{~J} / \mathrm{cm}^{2}[22]$ ). A possible solution is of course to reduce the fluence, but in this case stoichiometric transfer issues may arise [23]).

Generally the expansion velocities of the ionized species are found to be higher than those of the excited neutral species $[14,15,21]$. This trend seems to be generally followed in our experiments (see Figure 5), however some neutrals (e.g. Ga, see Table 1) can exhibit velocities comparable to those of the corresponding ions. This can be an evidence of a different ionization/excitation mechanism for this species, possibly resulting from in-plume collisional/radiative processes rather than directly from the ablation step.

In order to get some insight on the internal energies of the species present in the plume, the excitation temperature can be calculated using the relative intensities of two or more spectral lines originating from the same ionization stage, based on the well-known Boltzmann plot method [20, 21]. An example is given in Figure 6 for La II (spectroscopic constants from [24] have been used). Excitation temperatures for other species, recorded at $\mathrm{z}=0.5 \mathrm{~mm}$ from the target, are summarized in Table 1. Note that these are somehow "averaged" temperatures, as the gate width of the detector was set to $1 \mu \mathrm{s}$. Although the temperature values are rather common for this range of laser fluences, one can easily remark the very low temperature of S II, which can also indicate a different excitation mechanism for this species (note also that neutral sulfur emission lines have not been present in the spectrum).

Deeper insight on the plasma plume dynamics can be granted by studying the space- and time-resolved profiles of the excitation temperature and electronic density. For temporal temperature profiles, this can be done from series of snapshots taken at a given distance and various delays with respect to the laser pulse (as those in Figure 4), calculating for each delay the ratio of two spectral lines intensities (this method was preferred here for simplicity and time-saving, instead of the "heavier" Boltzmann plot method used above to derive the "average" temperatures). Two examples are given in Figures 7-a and 7-b for the temporal evolution of $\mathrm{La}^{+}$(derived from the relative intensity of the $428.69 \mathrm{~nm}$ and $429.60 \mathrm{~nm}$ lines) at two distances from the target $(\mathrm{z}=0.5 \mathrm{~mm}$ and $1.55 \mathrm{~mm}$, respectively). The temporally-resolved (50 ns resolution) excitation temperatures obtained (roughly between $6500 \mathrm{~K}$ and $9500 \mathrm{~K})$ are consistent with the average value $(1 \mu \mathrm{s})$ found at $\mathrm{z}=0.5 \mathrm{~mm}$. 
Moreover, the temporal evolution of the electronic density $n_{e}$ can be calculated from the temperature temporal profile by using the relative intensities of the neutral atomic lines and singly-charged ionic lines according to the Saha-Eggert equation $[25,26]$. Using the $428.026 \mathrm{~nm}$ and $428.696 \mathrm{~nm}$ spectral lines of La* and $\mathrm{La}^{+}$, respectively, and the spectroscopic data from [24], we derived the temporal profiles of the electron density displayed in Figure 7. The electron density and temperature values (at least up to the onset of the oscillations) seem to be in fair agreement with previous studies performed at comparable fluences, but on completely different materials (Ag [27], $\mathrm{Cu}$ [28]). This somehow suggests a quite universal behavior in this range of fluence, which can be related [23] to the not so different cohesive energies (vaporization enthalpies) of e.g. Ag, $\mathrm{Cu}, \mathrm{Ga}$ and $\mathrm{La}$ (at least in pure solid samples). Note however that $\mathrm{S}$ is much more volatile (by two orders of magnitude), which can also explain the different behavior evidenced above. Nevertheless, the multiple maxima present in the temperature and electronic density profiles reveal a complex behavior of the plasma plume, probably driven by (excitation/ionization/recombination) collisions and electric interactions, leading to the idea of double-layer formation and self-structuring, as evidenced previously in [29-31]. Complementary investigations by electrical methods (Langmuir probes and time-of-flight mass spectrometry) are envisaged in order to validate or reject this hypothesis.

\section{Conclusions}

Dynamics of plasma generated by laser ablation of GLS chalcogenide has been investigated through fast ICCD imaging and time- and space-resolved optical emission spectroscopy. Axial velocities have been derived for several neutral and singly-ionized species. Using the relative intensity method, the spatio-temporal evolution of both excitation temperature and electronic density has been investigated. The results evidenced a complex plasma formation with possible self-structuring behavior. These findings may have practical implications for pulsed laser deposition of amorphous chalcogenide thin films. A systematic study (using also electrical characterization methods, e.g. Langmuir probes) on the deposition conditions (including ablation laser pulse duration - ns, ps and fs) is therefore planned.

\section{Acknowledgments}

This work was supported by the Conseil Régional Nord Pas de Calais and the Fonds Européen de Développement Economique des Régions in the frame of the CPER CIA project and by a grant of the Romanian National Authority for Scientific Research, CNCS - UEFISCDI, project number PN-II-ID-PCE-2011-3-0650

\section{References}

1. V. Nazabal, F. Charpentier, J.-L. Adam, P. Nemec, H. Lhermite, M.-L. Brandily-Anne, J. Charrier, J.-P. Guin, A. Moréac, Int. J. Appl. Ceram. Tec. 8 (2011) 990.

2. M. Frumar, B. Frumarova, T. Wagner, M. Hrdlicka, J. Mater. Sci.: Mater. Electron. 18 (2007) S169.

3. M. Frumar, B. Frumarova, P. Nemec, T. Wagner, J. Jedelsky, M. Hrdlicka, J. Non-Cryst. Solids 352 (2006) 544.

4. J. S. Sanghera and I. D. Aggarwal, J. Non-Cryst. Solids 257 (1999) 6.

5. S. R. Elliott, Physics of Amorphous Materials, $2^{\text {nd }}$ edition, Longman Scientific \& Technical, Essex, United Kingdom (1990).

6. M. Guittard, A.M. Loireau-Lozach, F. Berguer, S. Barnier, J. Flahaut, J. Solid State Chem. 62 (1986).

7. J. Flahaut, M. Guittard, A.M. Loireau-Lozach, Glass Technol. 24 (1986) 149.

8. A. Mairaj, D. Hewak, D. J. Brady, P. Jander, T. Schweizer, Y. W. West, Electron. Lett. 32 (1996) 384.

9. V. Nazabal, M. Cathelinaud, W. Shen, P. Němec, F. Charpentier, H. Lhermite, M.-L. Anne, J. Capoulade, F. Grasset, A. Moréac, S. Inoue, M. Frumar, J.L. Adam, M. Lequime, C. Amra, Appl. Optics 47 (2008) C114.

10. A. Zakery, S.R. Elliott, Optical Nonlinearities in Chalcogenide Glasses and their Applications, SpringerVerlag, Berlin, Germany (2007).

11. K. Tanaka, K. Shimakawa, Phys. Status Solidi B 246 (2009) 1744.

12. M. Frumar, B. Frumarova, T. Wagner, P. Nemec, in: A.V. Kolobov (Ed.), Photo-Induced Metastability in Amorphous Semiconductors, Wiley-WCH, Weinheim, Germany (2003) pp. 23. 
13. K.E. Youden, T. Grevatt, R.W. Eason, H.N. Rutt, R.S. Deol, G. Wylangowski, Appl. Phys. Lett. 63 (1993) 1601.

14. C. Focsa, P.Nemec, M. Ziskind, C. Ursu, S. Gurlui, V. Nazabal, Appl. Surf. Sci. 255 (2009) 5307.

15. M.S.B. Darby, T.C. May-Smith, R.W. Eason, T. Donnelly, J.G. Lunney, K.D. Rogers, Appl. Surf. Sci. 254 (2008) 3364.

16. S.D. Pangavhane, P. Nemec, T. Wagner, J. Janča, J. Havel, Rapid Commun. Mass Spectrom. 24 (2010) 2000.

17. C. Mihesan, S. Gurlui, M. Ziskind, B. Chazallon, G. Martinelli, H. Zeghlache, M. Guignard, V. Nazabal, F. Smektala, C. Focsa, Appl. Surf. Sci. 248 (2005) 224.

18. S. Gurlui, M. Agop, P. Nica, M. Ziskind, C. Focsa, Phys. Rev. E 78 (2008) 026405.

19. P. Nica, P. Vizureanu, M. Agop, S. Gurlui, C. Focsa, N. Forna, P.D. Ioannou, Z. Borsos, Jpn J. Appl. Phys. 48 (2009) 066001.

20. C. Ursu, S.Gurlui, C. Focsa, G. Popa, Nucl. Instrum. Meth. B 267 (2009) 446.

21. C. Ursu, O. G. Pompilian, S. Gurlui, P. Nica, M. Agop, M. Dudeck, C. Focsa, Appl. Phys. A 101 (2010) 153.

22. S. Fähler, K. Sturm, H.-U. Krebs, Appl. Phys. Lett. 72 (1998) 1829.

23. J. Schou, Appl. Surf. Sci. 255 (2009) 5191.

24. R.L. Kurucz, B. Bell, 1995 Atomic Line Data, Kurucz CD-ROM No. 23. Cambridge, Mass.: Smithsonian Astrophysical Observatory, http://www.cfa.harvard.edu/amp/ampdata/kurucz23/sekur.html

25. P.W.J.M. Boumans, in: E.L. Grove (Ed.), Analytical Emission Spectroscopy, Dekker, New York (1972) Vol.1, Part 2.

26. H. R. Griem, Plasma Spectroscopy, McGraw-Hill, New York (1964).

27. B. Toftmann, J. Schou, T.N. Hansen, J.G. Lunney, Phys. Rev. Lett. 84 (2000) 3998.

28. J.M. Hendron, C.M.O. Mahony, T. Morrow, W.G. Graham, J. Appl. Phys. 81 (1997) 2131.

29. S. Eliezer, H. Hora, Phys. Rep. 172 (1989) 339.

30. S. Gurlui, M. Sanduloviciu, M. Strat, G. Strat, C. Mihesan, M. Ziskind, C. Focsa, J. Optoelectron. Adv. Mater. 8 (2006) 148.

31. P. Nica, M. Agop, S. Gurlui, C. Focsa, Europhys. Lett. 89 (2010) 65001. 


\section{Figure captions}

Figure 1. Schematic view of the experimental set-up.

Figure 2. Temporal evolution of the spectrally-integrated optical emission of the plasma plume obtained by laser ablation of the GLS sample. Successive laser pulses of equal energy $\left(15 \mathrm{~mJ}\right.$, fluence $\left.=4 \mathrm{~J} / \mathrm{cm}^{2}\right)$ were used to record the snapshots at different delays.

Figure 3. Optical emission spectrum of a $0.2 \mathrm{~mm}$-wide plasma slice centered at $\mathrm{z}=0.5 \mathrm{~mm}$ from the target surface (gate width $=1 \mu \mathrm{s}$, delay $=25 \mathrm{~ns}$, laser fluence $=4 \mathrm{~J} / \mathrm{cm}^{2}$ ).

Figure 4. Optical emission time-of-flight profiles recorded for various neutrals and ions spectral lines at $\mathrm{z}=0.5$ $\mathrm{mm}$ from the target surface (gate width $=50 \mathrm{~ns}$, laser fluence $=4 \mathrm{~J} / \mathrm{cm}^{2}$ ).

Figure 5. Axial velocities of various $\mathrm{Ga}$, La, and $\mathrm{S}$ species derived from the space-time evolution of spectral lines (gate width $=50 \mathrm{~ns}$, laser fluence $=4 \mathrm{~J} / \mathrm{cm}^{2}$ ).

Figure 6. Boltzmann plot for calculation of the average excitation temperature (gate width $=1 \mu \mathrm{s}$ ) of La II at $\mathrm{z}=$ $0.5 \mathrm{~mm}$ from the target surface (laser fluence $=4 \mathrm{~J} / \mathrm{cm}^{2}$ ).

Figure 7. Excitation temperature and electronic density temporal profiles recorded at $\mathrm{z}=0.5 \mathrm{~mm}(\mathrm{a})$ and $\mathrm{z}=1.55$ $\mathrm{mm}$ (b) from the target surface (laser fluence $=4 \mathrm{~J} / \mathrm{cm}^{2}$ ).

\section{Table caption}

Table 1. Axial velocities and average excitation temperatures (at $0.5 \mathrm{~mm}$ from the target, $1 \mu \mathrm{s}$ gate width, laser fluence $=4 \mathrm{~J} / \mathrm{cm}^{2}$ ) of some species present in the plasma plume. 


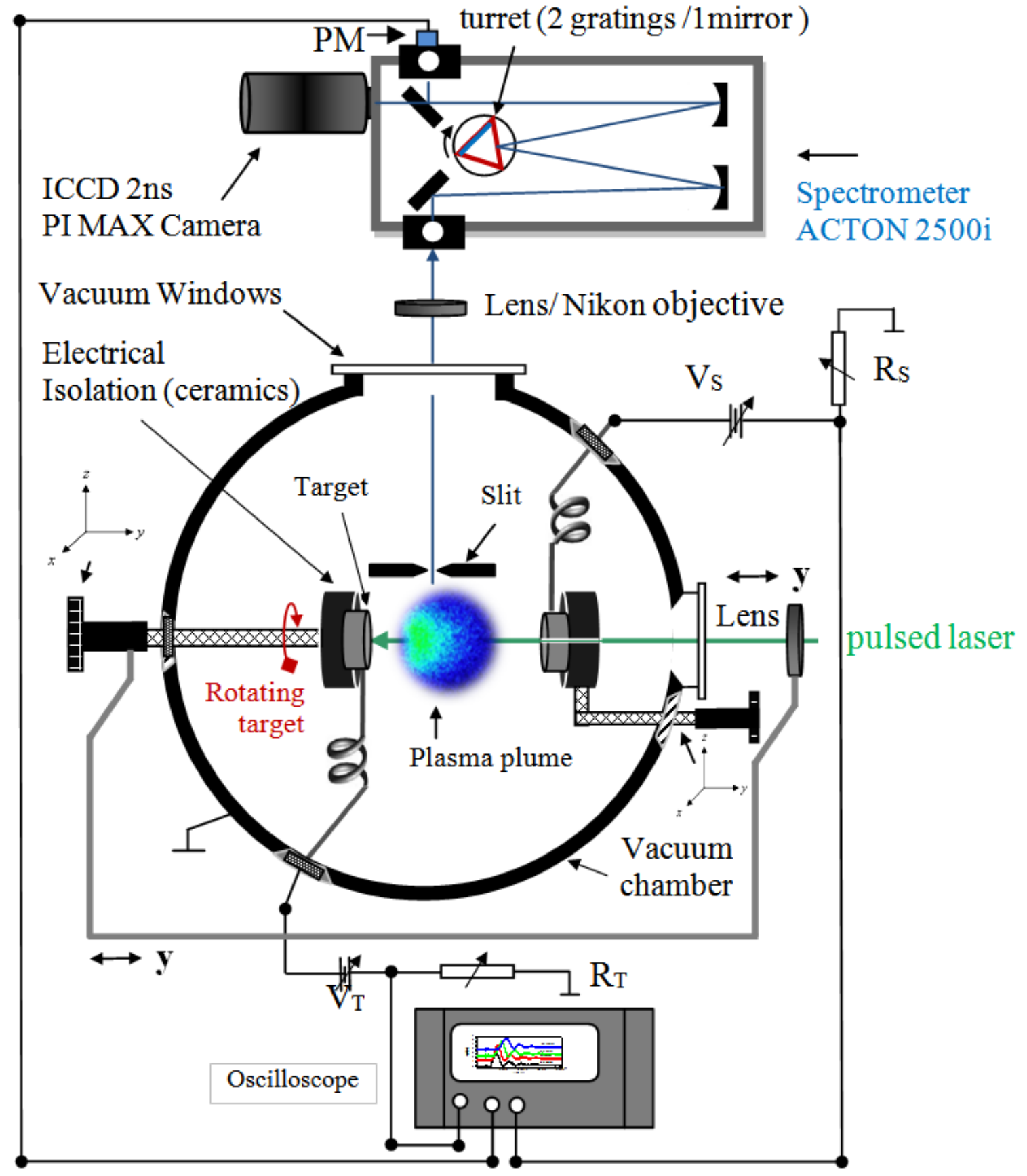

Figure 1. Schematic view of the experimental set-up. 


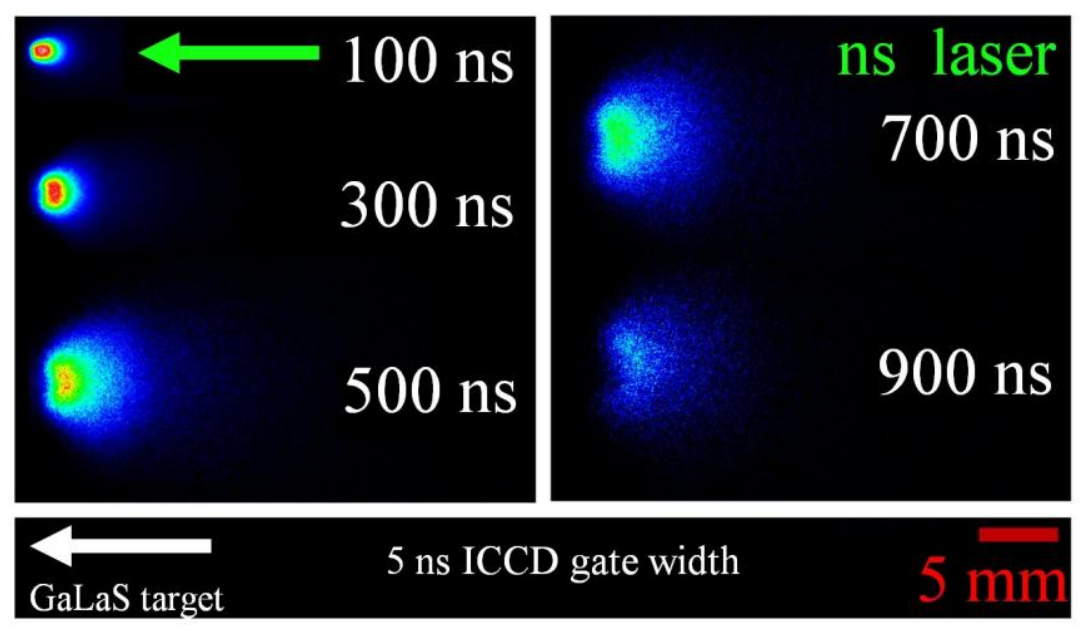

Figure 2. Temporal evolution of the spectrally-integrated optical emission of the plasma plume obtained by laser ablation of the GLS sample. Successive laser pulses of equal energy $\left(15 \mathrm{~mJ}\right.$, fluence $\left.=4 \mathrm{~J} / \mathrm{cm}^{2}\right)$ were used to record the snapshots at different delays. 


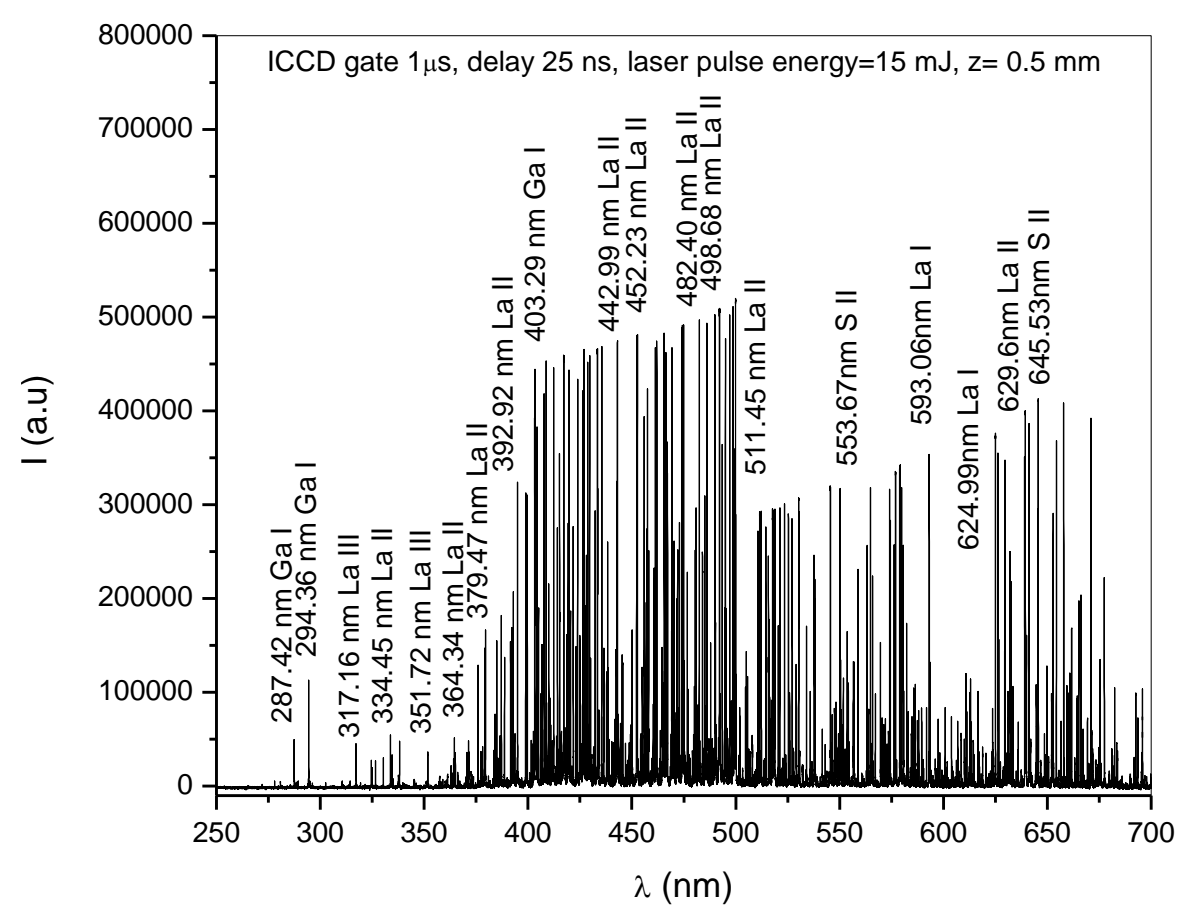

Figure 3. Optical emission spectrum of a $0.2 \mathrm{~mm}$-wide plasma slice centered at $\mathrm{z}=0.5 \mathrm{~mm}$ from the target surface $\left(\right.$ gate width $=1 \mu \mathrm{s}$, delay $=25 \mathrm{~ns}$, laser fluence $=4 \mathrm{~J} / \mathrm{cm}^{2}$ ). 


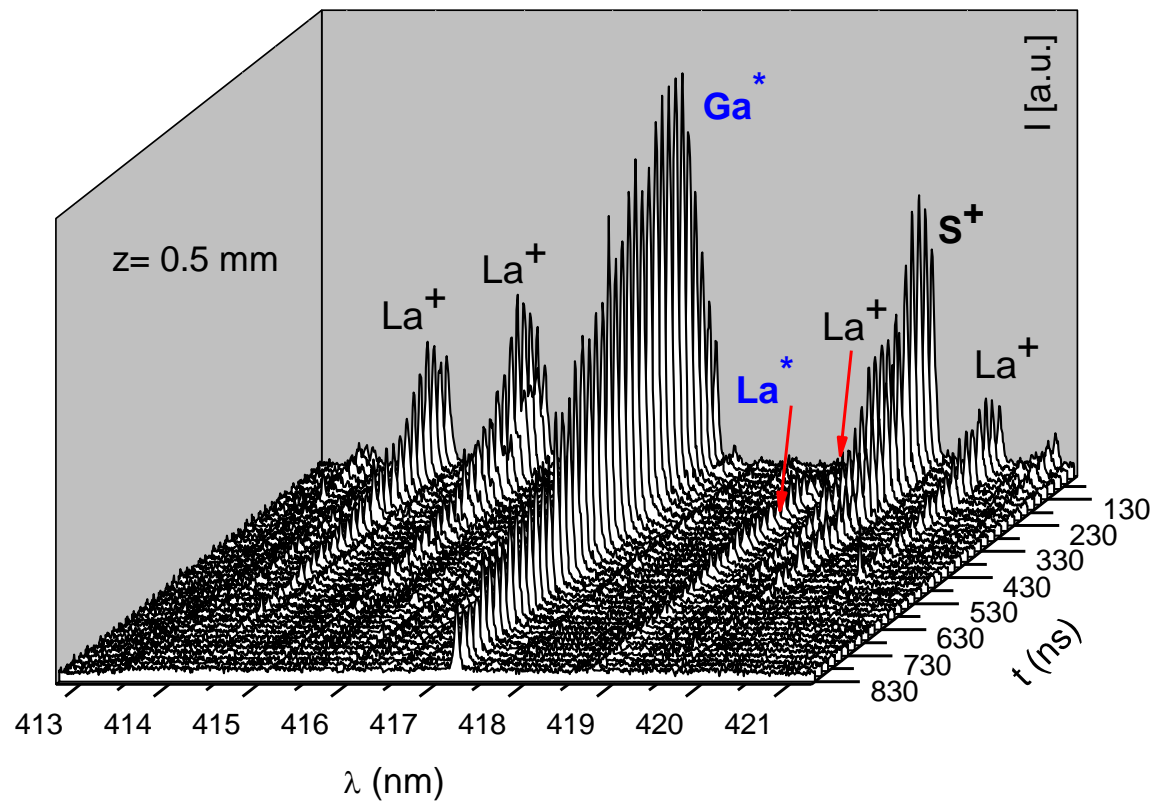

Figure 4. Optical emission time-of-flight profiles recorded for various neutrals and ions spectral lines at $\mathrm{z}=0.5$ $\mathrm{mm}$ from the target surface (gate width $=50 \mathrm{~ns}$, laser fluence $=4 \mathrm{~J} / \mathrm{cm}^{2}$ ). 


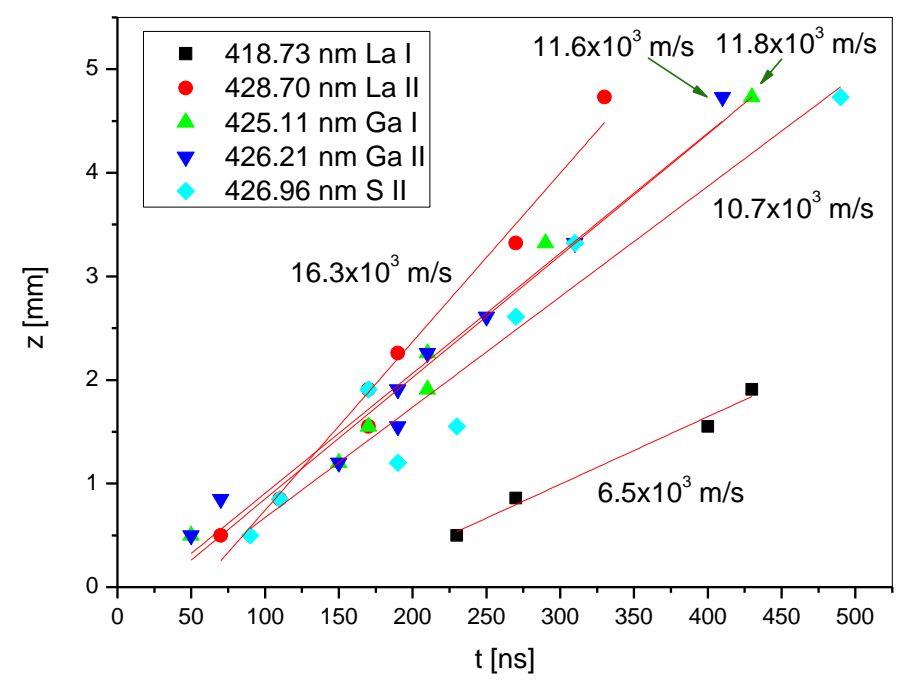

Figure 5. Axial velocities of various $\mathrm{Ga}, \mathrm{La}$, and $\mathrm{S}$ species derived from the space-time evolution of spectral lines (gate width $=50 \mathrm{~ns}$, laser fluence $=4 \mathrm{~J} / \mathrm{cm}^{2}$ ). 


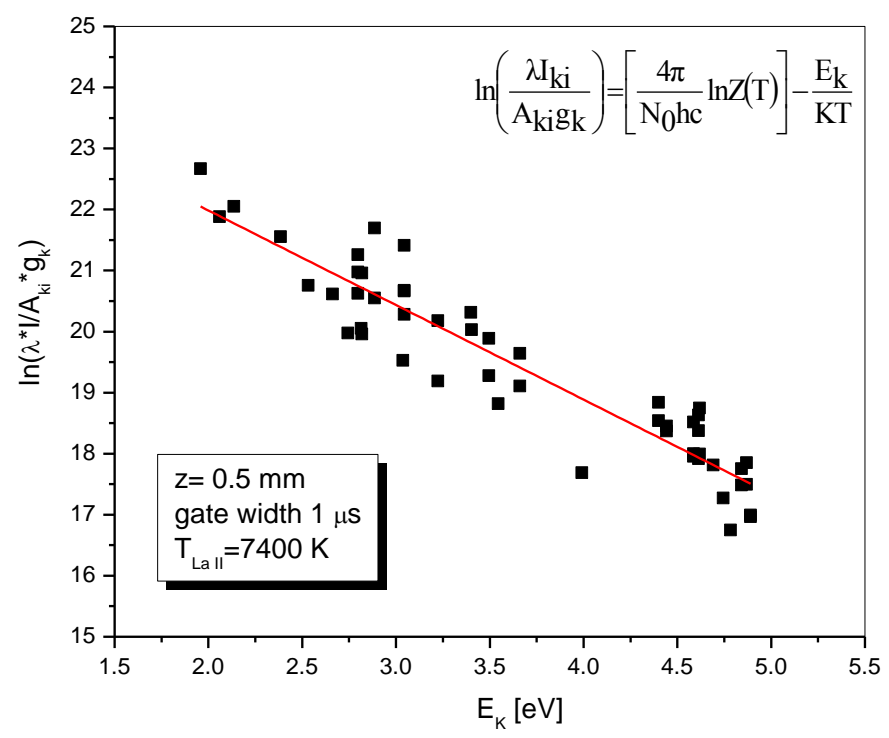

Figure 6. Boltzmann plot for calculation of the average excitation temperature (gate width $=1 \mu \mathrm{s}$ ) of La II at $\mathrm{z}=$ $0.5 \mathrm{~mm}$ from the target surface (laser fluence $=4 \mathrm{~J} / \mathrm{cm}^{2}$ ). 

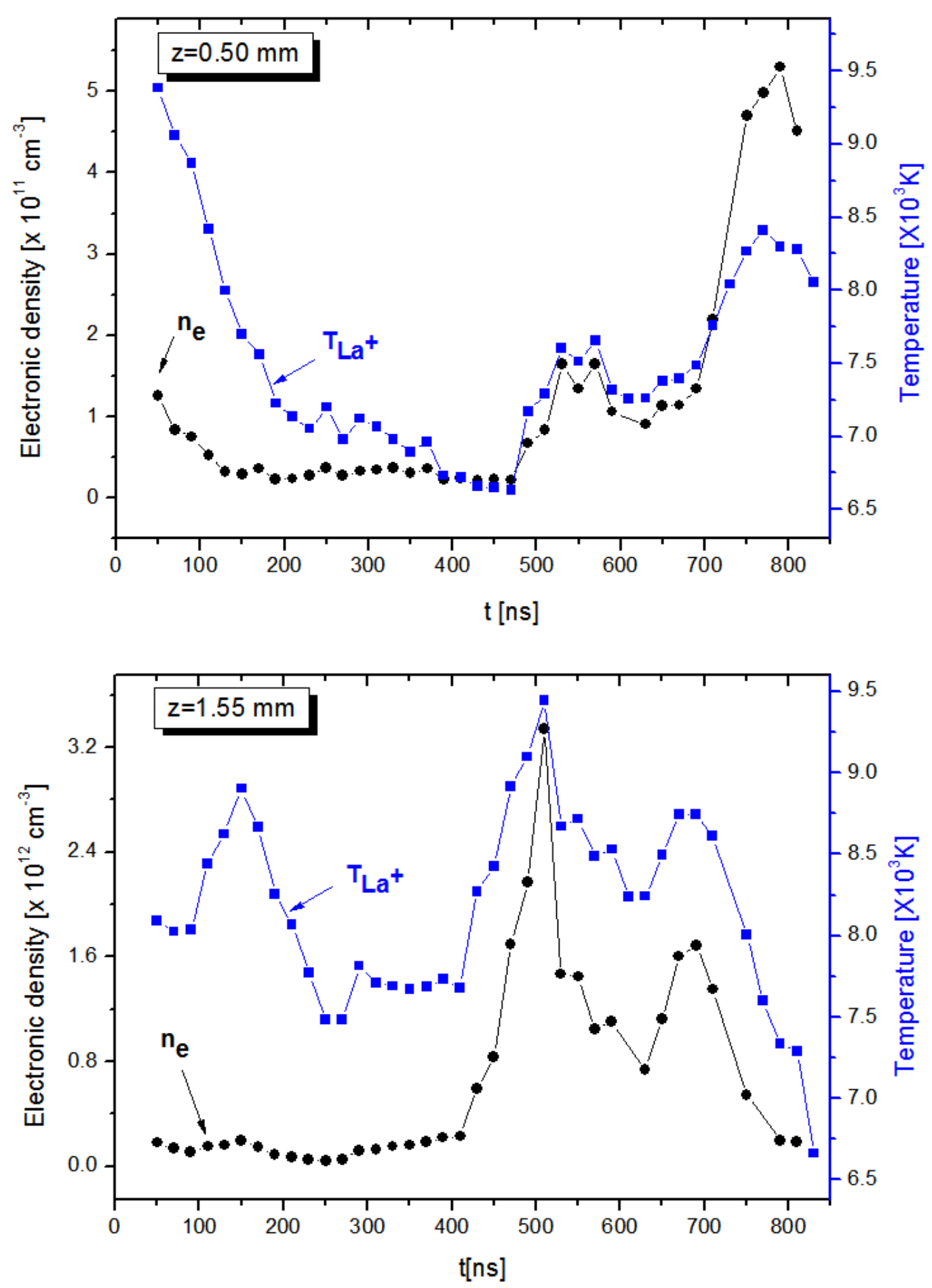

Figure 7. Excitation temperature and electronic density temporal profiles recorded at $\mathrm{z}=0.5 \mathrm{~mm}$ (a) and $\mathrm{z}=1.55$ $\mathrm{mm}$ (b) from the target surface (laser fluence $=4 \mathrm{~J} / \mathrm{cm}^{2}$ ). 
Table 1. Axial velocities and average excitation temperatures (at $0.5 \mathrm{~mm}$ from the target, $1 \mu$ s gate width, laser fluence $=4 \mathrm{~J} / \mathrm{cm}^{2}$ ) of some species present in the plasma plume.

\begin{tabular}{|c|c|c|}
\hline Species & Velocity $\left[10^{3} \mathrm{~m} / \mathrm{s}\right]$ & Excitation temperatures $\left[10^{3} \mathrm{~K}\right]$ \\
\hline Ga I $(\lambda=417.20 \mathrm{~nm})$ & 9.9 & 4.3 \\
\hline Ga I $(\lambda=425.11 \mathrm{~nm})$ & 11.8 & 4.3 \\
\hline Ga II $(\lambda=426.21 \mathrm{~nm})$ & 11.6 & 5.3 \\
\hline La I $(\lambda=418.73 \mathrm{~nm})$ & 6.5 & 5.3 \\
\hline La I $(\lambda=428.02 \mathrm{~nm})$ & 9.7 & 5.3 \\
\hline La I $(514.54 \mathrm{~nm})$ & 11.2 & 7.4 \\
\hline La II $(\lambda=428.70 \mathrm{~nm})$ & 16.3 & 1.4 \\
\hline S II $(\lambda=426.96 \mathrm{~nm})$ & 10.7 & \\
\hline
\end{tabular}


Figure 1

Click here to download high resolution image

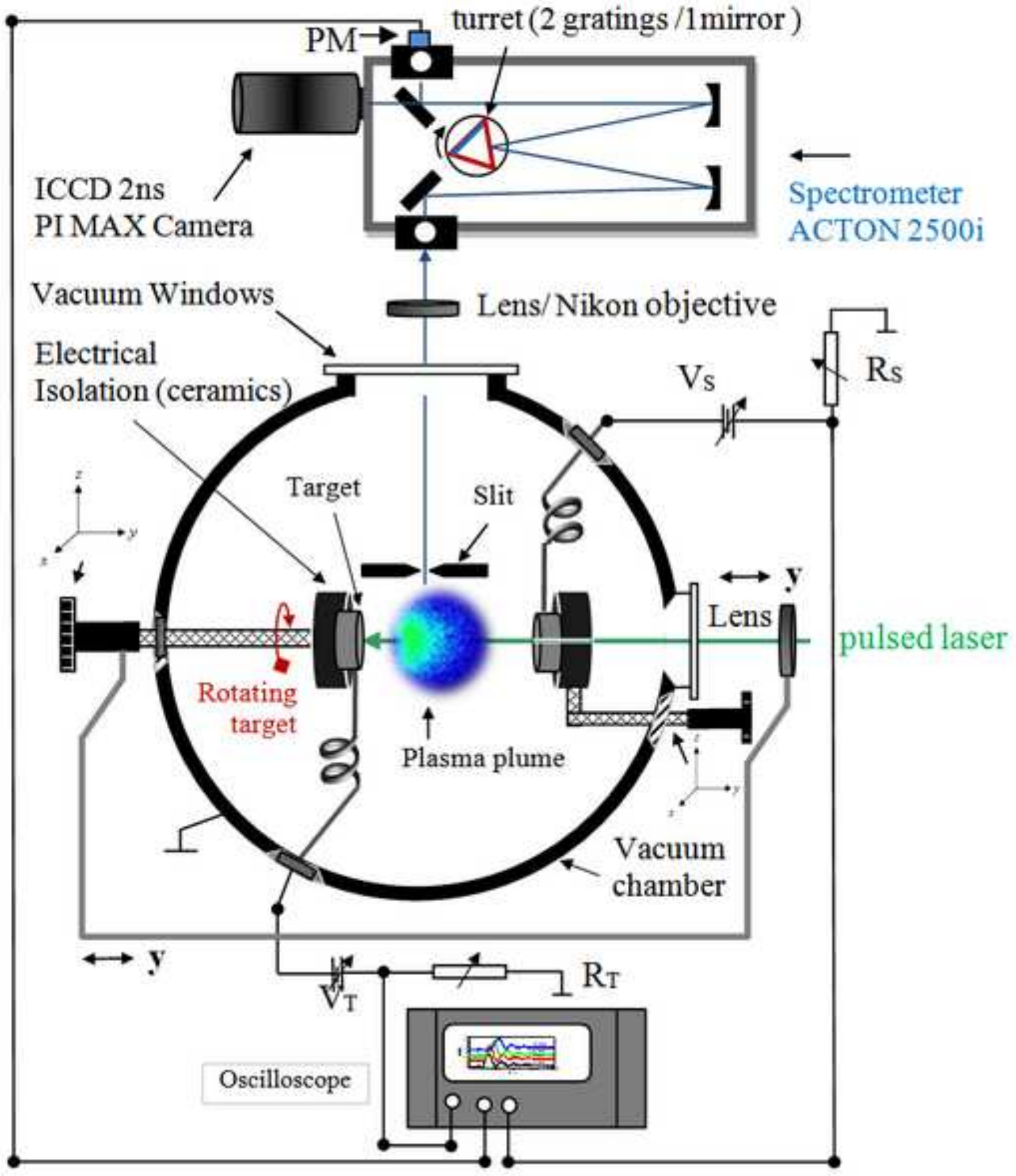




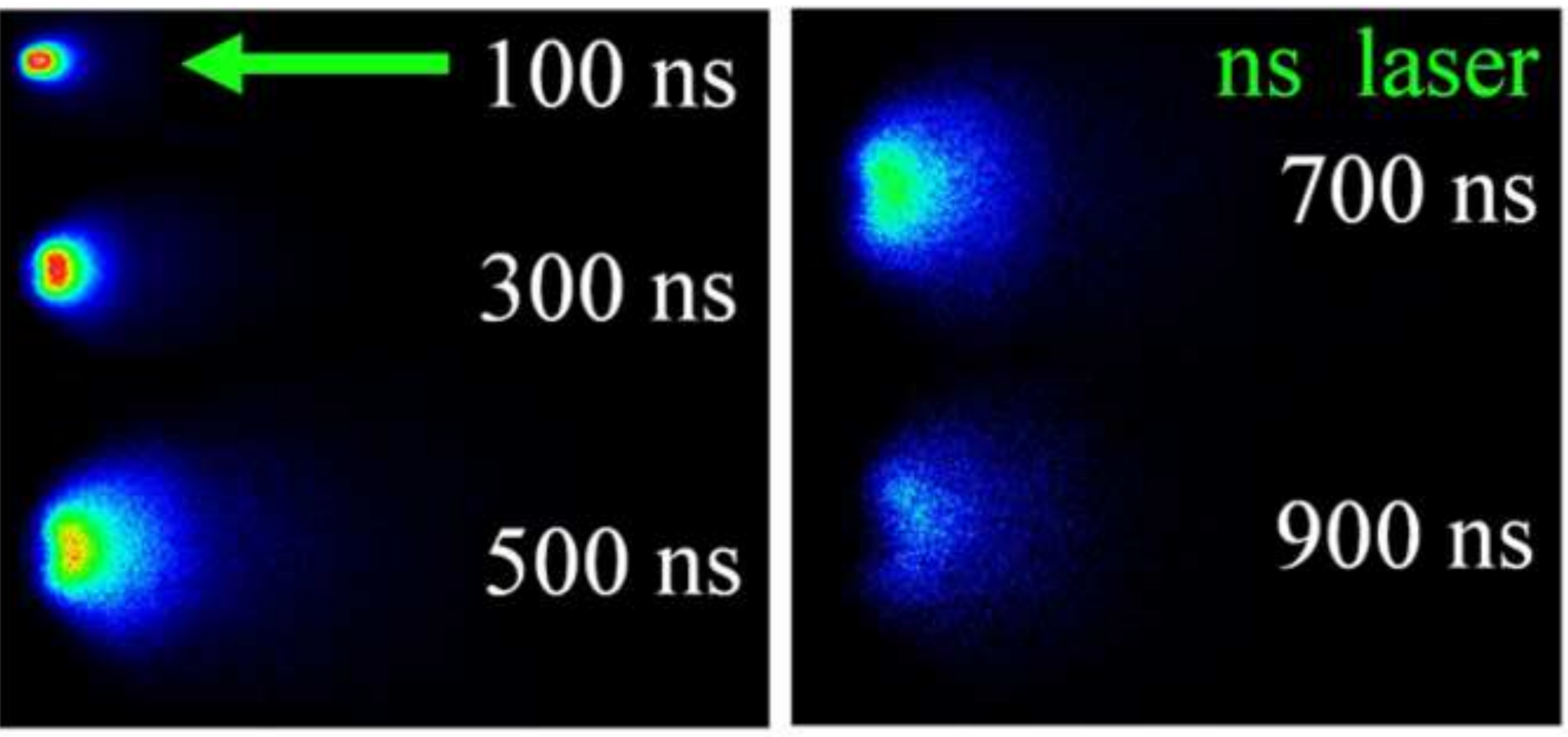

$\begin{array}{lll}\text { GaLaS target } & 5 \mathrm{~ns} \text { ICCD gate width } & 5 \mathrm{~mm}\end{array}$




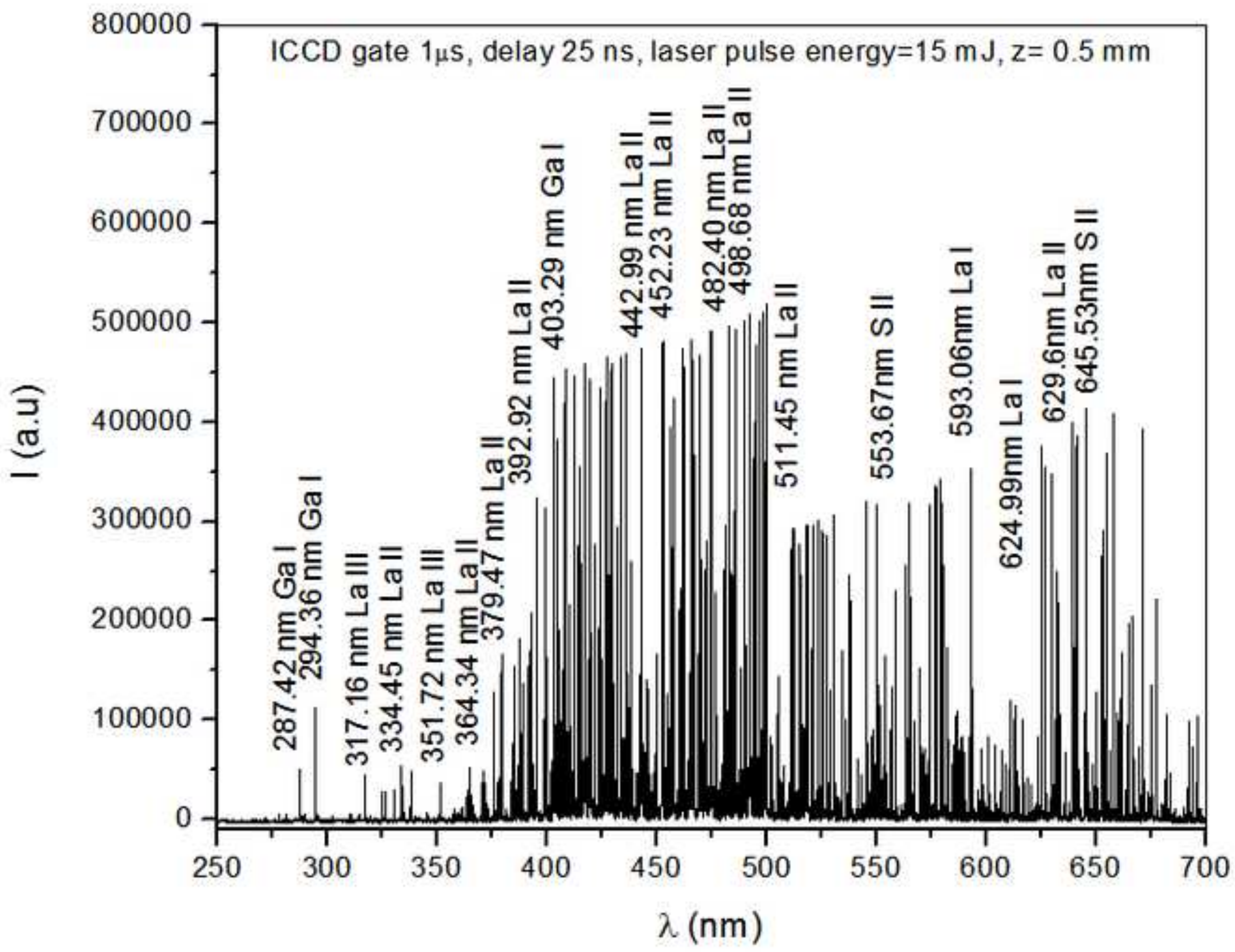




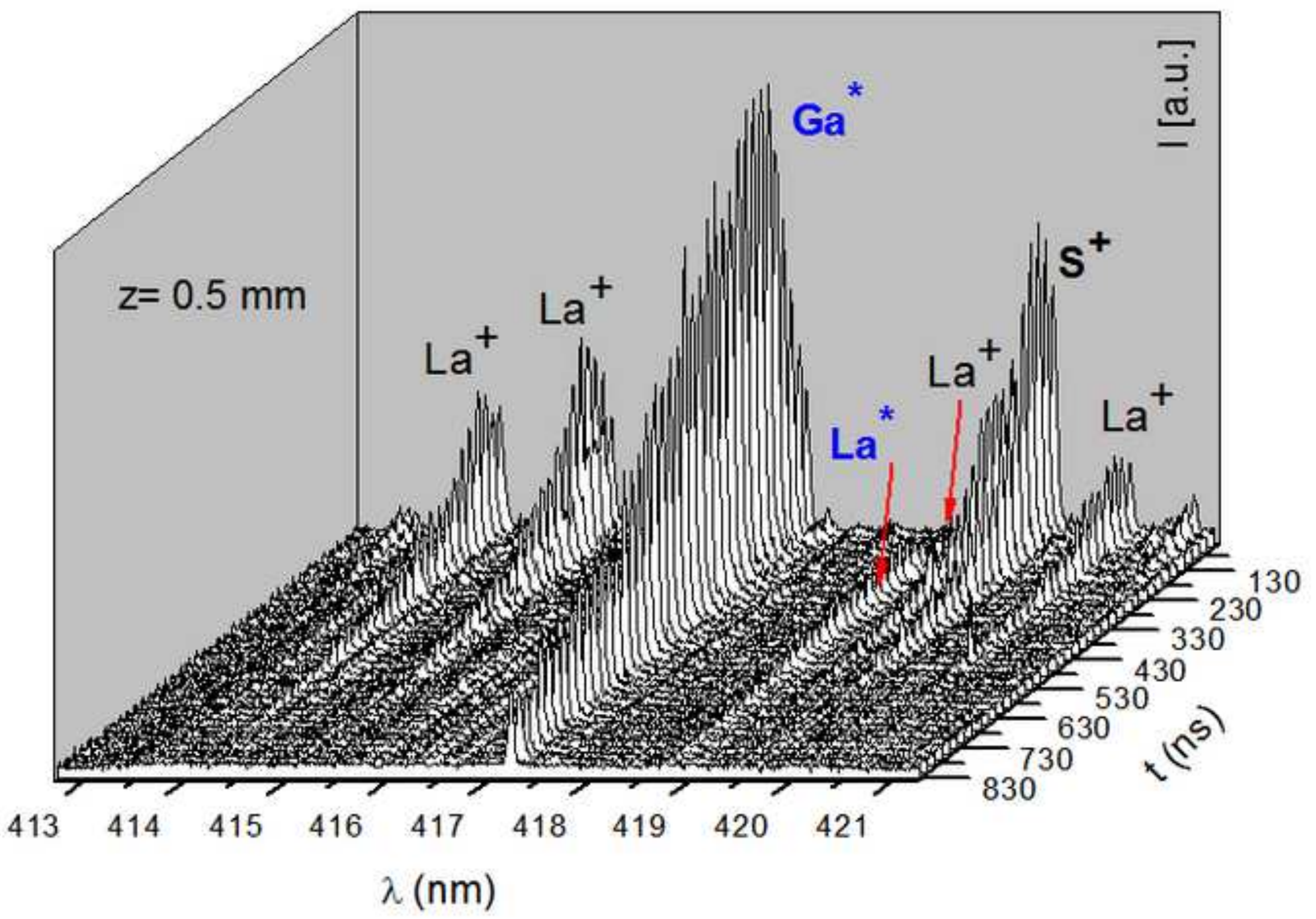




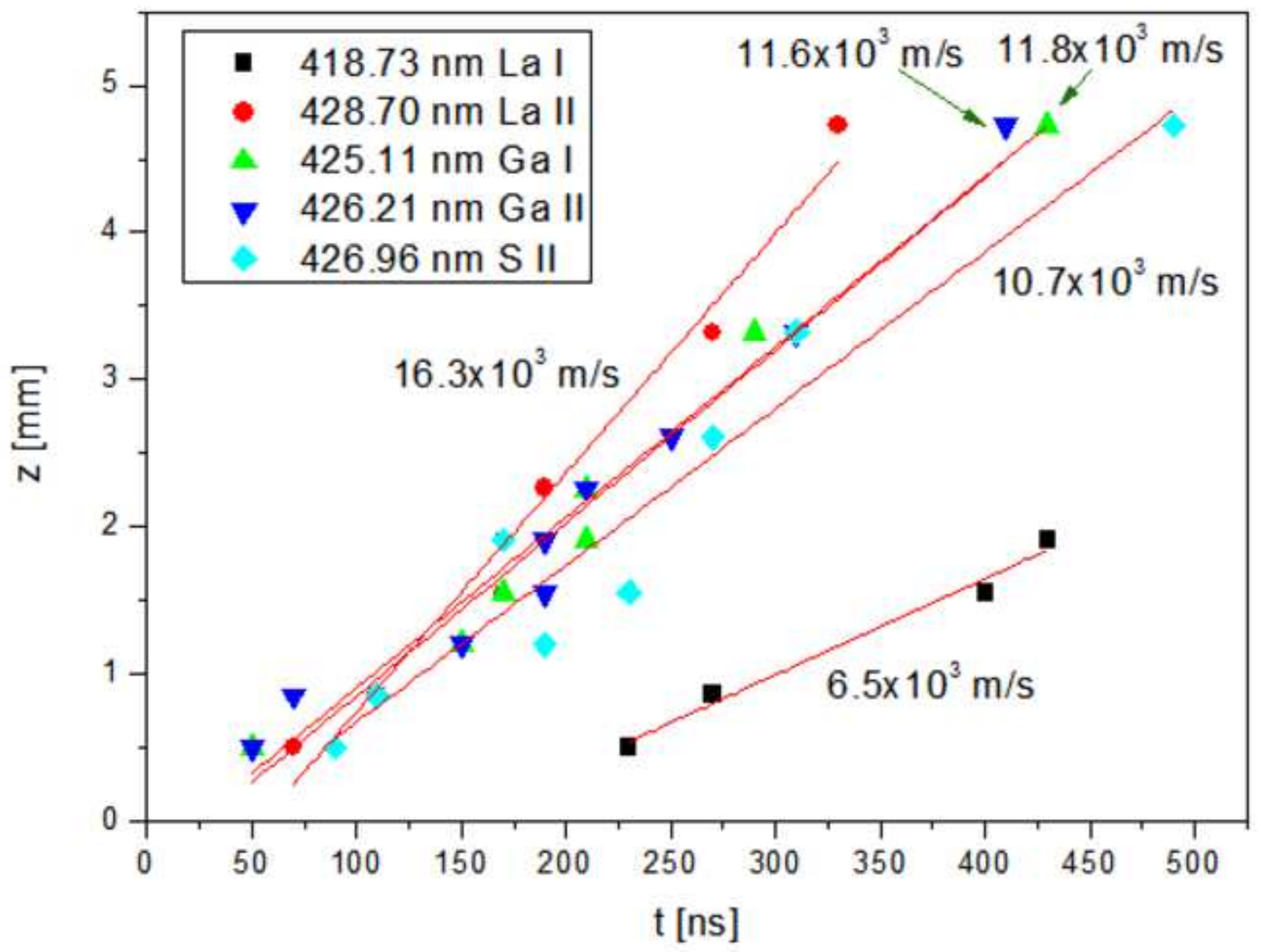


Click here to download high resolution image

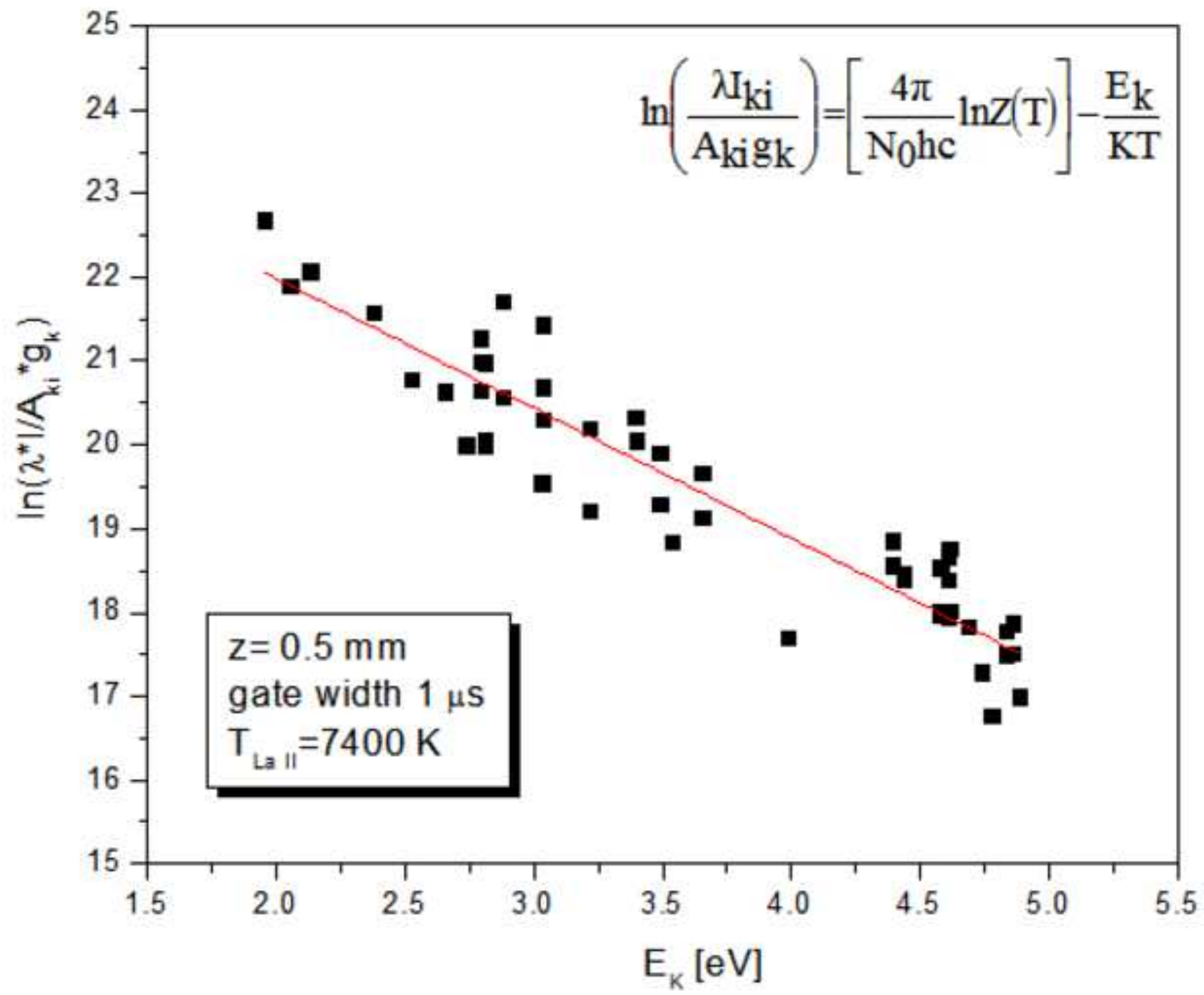



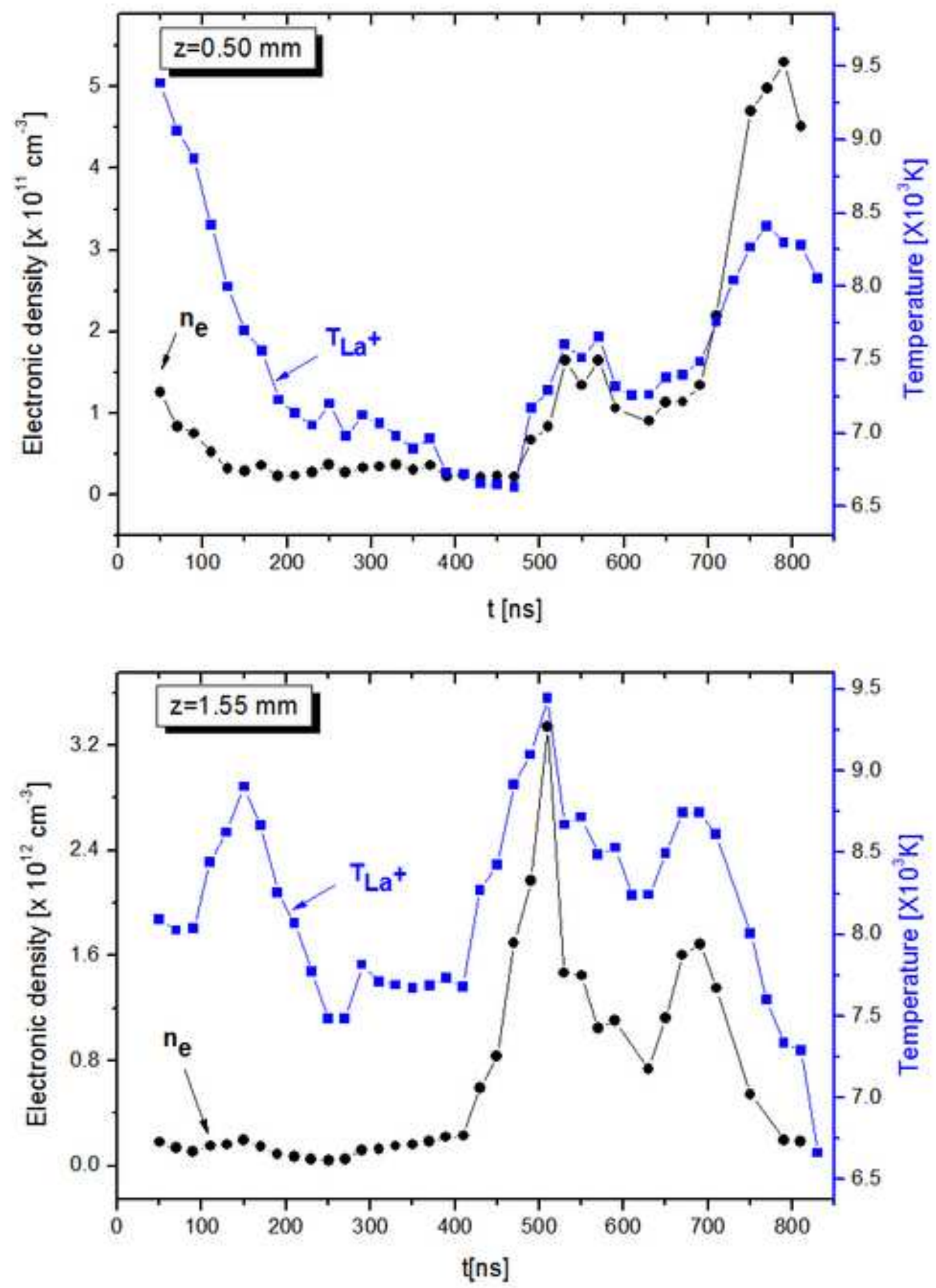
Table 1. Axial velocities and average excitation temperatures (at $0.5 \mathrm{~mm}$ from the target, $1 \mu \mathrm{s}$ gate width) of some species present in the plasma plume.

\begin{tabular}{|c|c|c|}
\hline Species & Velocity $\left[10^{3} \mathrm{~m} / \mathrm{s}\right]$ & Excitation temperatures $\left[10^{3} \mathrm{~K}\right]$ \\
\hline Ga I $(\lambda=417.20 \mathrm{~nm})$ & 9.9 & 4.3 \\
\hline Ga I $(\lambda=425.11 \mathrm{~nm})$ & 11.8 & 4.3 \\
\hline Ga II $(\lambda=426.21 \mathrm{~nm})$ & 11.6 & 5.3 \\
\hline La I $(\lambda=418.73 \mathrm{~nm})$ & 6.5 & 5.3 \\
\hline La I $(\lambda=428.02 \mathrm{~nm})$ & 9.7 & 5.3 \\
\hline La I $(514.54 \mathrm{~nm})$ & 11.2 & 7.4 \\
\hline La II $(\lambda=428.70 \mathrm{~nm})$ & 16.3 & 1.4 \\
\hline S II $(\lambda=426.96 \mathrm{~nm})$ & 10.7 & \\
\hline
\end{tabular}

